\title{
TRABALHO SOCIAL COM FAMÍLIAS EM SITUAÇÃO DE VIOLÊNCIA: ABORDAGEM ATRAVÉS DA EDUCAÇÃO PARA A PAZ
}

\section{SOCIAL WORK WITH FAMILIES IN THE SITUATION OF VIOLENCE: APPROACH THROUGH EDUCATION FOR PEACE}

\author{
Juliano Del Gobo* \\ Virginia de Souza
}

\begin{abstract}
RESUMO
O presente artigo objetiva aproximar Cultura da Paz e Assistência Social, relacionando os temas em uma proposta de educação para a paz através de trabalho social com famílias com históricos de violência intrafamiliar e comunitária, atendidas por serviços de assistência social em um município de pequeno porte, da região dos Campos Gerais- PR. A assistência social, a partir da Constituição Federal de 1988, tornou-se compromisso do Estado, por meio da oferta de serviços continuados visando proteção social e a garantia de direitos a indivíduos e famílias em situação de vulnerabilidade e risco social. No ano de 2014, especificamente no departamento de proteção social especial, desenvolveu-se um trabalho social com família a partir de metodologias e dinâmicas de grupos baseados na educação para a paz. No primeiro grupo, formado pelas famílias, trabalhou-se com os 10 passos para a cultura da paz. O segundo e terceiro grupo, formado pelos adolescentes, trabalhou-se com quatro eixos centrais: "modo de ser"; "aprender"; "conscientizarse" e "fazer escolhas". A experiência apresentada nos deu mais propriedade para afirmar a potencial relação que existe entre o trabalho social com famílias no âmbito da política de assistência social e cultura de paz.
\end{abstract}

Palavras-chaves: Cultura da Paz. Trabalho Social com Famílias. Violência.

\begin{abstract}
This article aims to bring a culture of peace and social assistance closer to the theme of a proposal of education for peace through social work with families with histories of intrafamily and community violence, assisted by social assistance services in a small municipality, of the Campos Gerais-PR region. Social assistance, as of the Federal Constitution of 1988, became a commitment of the State, through the provision of continuous services aimed at social protection and the guarantee of rights to individuals and families in situations of vulnerability and social risk. In the year 2014, specifically in the department of special social protection, a social work with family was developed from methodologies and dynamics of groups based on education for peace. In the first group, formed by families, worked with the 10 steps for the culture of peace. The second and third group, formed by the adolescents, worked with four central axes: "way of being"; "learn"; "Make yourself aware" and "make choices". The experience presented gave us more property to affirm the potential relationship that exists between social work with families within the framework of social assistance policy and culture of peace.
\end{abstract}

Keywords: Culture of Peace. Social Work with Families. Violence.

\footnotetext{
"Mestre em Ciências Sociais Aplicadas pela Universidade Estadual de Ponta Grossa. - PR. Docente do curso de Psicologia nas Faculdades Cescage - Ponta Grossa, PR. E-mail: jdg.psicologia@gmail.com

"* Doutoranda do Programa de Pós Graduação em Ciências Sociais Aplicadas pela Universidade Estadual de Ponta Grossa - PR; Mestrado em Ciências Sociais (2008); Bacharel em Serviço Social (1996). Atua como assistente social no município de Carambeí, PR. E-mail: vssato@yahoo.com.br
} 


\section{INTRODUÇÃO}

Pensar em cultura da paz é pensar a partir de uma consciência permanente dos valores da não violência social. Pensar em assistência social é pensar que todo cidadão tem direito a proteção social, na perspectiva da universalização de acesso aos direitos sociais e a condições dignas de vida. A compreensão sobre cultura da paz vai além de atitudes que visam construir paz, ela pressupõe mudança de paradigmas em relação a conflitos e violência, violência esta, que por vezes encontra-se naturalizada através de relações autoritárias em família, no despotismo do trabalho, nas relações interpessoais e comunitárias. A assistência social, enquanto direito do cidadão vai para além de assistencialismo, caridade ou ações pontuais, ela constitui-se enquanto dever do Estado enquanto promotor de políticas públicas que assegurem a garantia da vida, redução de danos e prevenção da incidência de riscos, especialmente a proteção à família, à maternidade, à infância, à adolescência e à velhice (BRASIL, 1993).

A partir da Constituição Federal de 1988, a assistência social vem se constituindo através de princípios democráticos, afirmando a universalização dos direitos sociais e o respeito à dignidade do cidadão em sua autonomia e em seu direito a acessar benefícios e serviços de qualidade, de conviver em segurança na família e na comunidade. Além disso, reconhece certas vicissitudes da vida natural ou social, tais como a velhice, a doença, o infortúnio e as privações decorrentes de uma estrutura social que torna seletiva, certas formas de distribuição e redistribuição de bens materiais (como a comida e o dinheiro) e de bens culturais (os diferentes saberes) que determinam a condição humana, a partir das condições materiais de sobrevivência e a integração humana, sob várias formas na vida social (BRASIL, 2005).

Para Paulo Freire, "[...] viver em uma cultura de paz significa repudiar todas as formas de violência, especialmente a cotidiana, e promover os princípios de liberdade, justiça, solidariedade e tolerância, bem como, estimular a compreensão entre os povos e as pessoas" (FREIRE apud MILAN, 2003, p.36). Na perspectiva desse educador brasileiro, a educação, seja ela formal ou informal deve se voltar para ensinar a conviver e não somente para sobreviver. A partir dessa interlocução com o educador brasileiro é que cultura de paz se aproxima de uma das finalidades da assistência social no Brasil. A partir dessa perspectiva, pode-se refletir sobre valores e condutas que constituem a dimensão subjetiva da sociedade brasileira, constituída historicamente, num permanente movimento e um permanente processar do homem em sociedade (BOCK, 1998) e resulta que assistência social e cultura da paz se alinham através dos princípios de liberdade, justiça e solidariedade.

Diante desses elementos, o presente artigo objetiva articular aspectos teóricos e metodológicos da política de assistência social e da cultura da paz, articulando tal discussão por meio de uma experiência concreta envolvendo o trabalho social junto a famílias com históricos de violência intrafamiliar e comunitária, atendidas por serviços de assistência social. A princípio o artigo fará uma breve exposição sobre o tema violência buscando indicadores da realidade brasileira. Na sequência se abordará sobre educação para a paz, tendo como base os parâmetros estabelecidos pela UNESCO, bem como, as reflexões de Paulo Freire em que afirma uma cultura de reconhecimento de direitos humanos. Em seguida, uma breve apresentação da política de assistência social, na perspectiva de garanta de direitos e o relato do trabalho social realizado com família em vivência de situação de violência.

O trabalho foi desenvolvido em um município de pequeno porte ${ }^{1}$, situado na região dos Campos Gerais- PR, na Secretaria Municipal de Assistência Social, especificamente no departamento de proteção social especial. Utilizou-se como metodologia, o trabalho com grupos, a princípio com a família das crianças e adolescentes em medida de proteção e o segundo e terceiro grupos com os próprios adolescentes. No primeiro grupo, formado pelas famílias, trabalhou-se com os 10 passos para a cultura da paz. $\mathrm{O}$ segundo e terceiro grupo, formado pelos adolescentes, trabalhou-se com 4 eixos centrais: "modo de ser"; "aprender"; "conscientizar-se" e "fazer escolhas". O trabalho foi desenvolvido com oficinas planejadas a partir de temas centrais, bem como roda de conversas e dinâmicas de grupo. Ao final do processo de trabalho foi realizada uma avaliação conjunta entre as famílias

\footnotetext{
${ }^{1}$ Optou-se por não identificar o município no qual foi realizado o trabalho, por constituir-se de atendimento a crianças e adolescentes em medida de proteção, com direitos violados, ou adolescentes em conflito com a lei.
} 
e os profissionais da equipe multidisciplinar, responsável pelo serviço.

\section{A VIOLÊNCIA ENQUANTO EXPRESSÃO NO COTIDIANO SOCIAL}

Quando falamos em violência, pode-se ter em mente que se trata de um assunto de Segurança Pública, ou mesmo para o terreno criminal, porém se formos mais fundo na temática, perceberemos que se trata de um problema bem mais amplo, trata-se de um fenômeno social. A violência constitui-se um fenômeno multicausal e por este motivo não pode ser tratada somente pelo viés criminal, mas também pelo aspecto social.

Para Minayo (2006), a violência pode ser classificada em: a) estrutural - a que deriva da desigualdade na distribuição da riqueza social, incidindo sobre a condição de vida das pessoas; b) cultural - manifesta-se nas relações de dominação entre grupos; c) delinquência - diz respeito à execução de ações criminosas.

Conforme Minayo (2006), nos anos 1960 o campo médico começou a discutir, estudar e a diagnosticar algumas situações que envolviam a violência, enfocaram a princípio a chamada síndrome do bebê espancado, hoje conhecido como síndrome do bebê sacudido. Naquela ocasião colocou-se esta problemática como um sério problema para o crescimento e o desenvolvimento infantil. Diante disto, vários países, como os Estados Unidos, começaram a criar, dentro dos setores sociais e de saúde programas para prevenir a violência intrafamiliar; problema até então tratado como foro íntimo, privado, passou a tornar-se de foro público.

Nos anos 1970, a violência contra a mulher começa a ter maior visibilidade, junto aos movimentos feministas. Neste movimento buscava-se sensibilizar as mulheres e a sociedade contra a opressão e a dominação proveniente da cultura patriarcal.

Segundo Minayo:

No Brasil, a inclusão da violência e da criminalidade na agenda da cidadania coincide com o término (oficial) da ditadura militar. Os movimentos sociais pela democratização, as instituições de direito e a forte pressão de algumas entidades não governamentais e organizações internacionais, com poder de influenciar o debate nacional, foram fundamentais para tornar a violência social uma questão pública (MINAYO, 2006, p.1262).

Com relação aos idosos, somente com o advento do Estatuto do Idoso em 2003, que se teve maior visibilidade sobre os direitos dos idosos, os quais, por vezes estavam sendo violados. Em 1975, pela primeira vez falou-se sobre abusos contra idosos, quando o British Medical Journal, num editorial denominado Granny-battering colocou esta situação em pauta na sociedade. No Brasil, o tema violência passou a fazer parte da agenda de discussão das Políticas Públicas a partir dos anos 1980, fato este considerado tardio (MINAYO, 2004).

A dimensão do problema é grande e tem aumentado na última década. Dados sobre as taxas de homicídio da população brasileira entre 2005 e 2015 traçam um cenário de tragédia social cotidiana. O Atlas da Violência - publicado pelo IPEA em 2017 apresenta que em 2015 houve 59.080 homicídios no Brasil - o que equivale a uma taxa por 100 mil habitantes de 28,9. Este dado veio a consolidar a mudança de patamar desse indicador (na ordem de 59 a 60 mil casos por ano) no país, superando o intervalo de 48 mil a 50 mil mortes, ocorridas entre 2005 e 2007. De 1980 a 2014, os casos de homicídio por arma de fogo aumentaram $600 \%$ em um crescimento populacional inferior a $100 \%$. E apesar de compor apenas $26 \%$ da população brasileira, os jovens entre 15 e 29 anos representam $59 \%$ das mortes por arma de fogo (WAISELFISZ, 2015). 
Gráfico 1.1 Homicídio no Brasil, 2005 a 2015

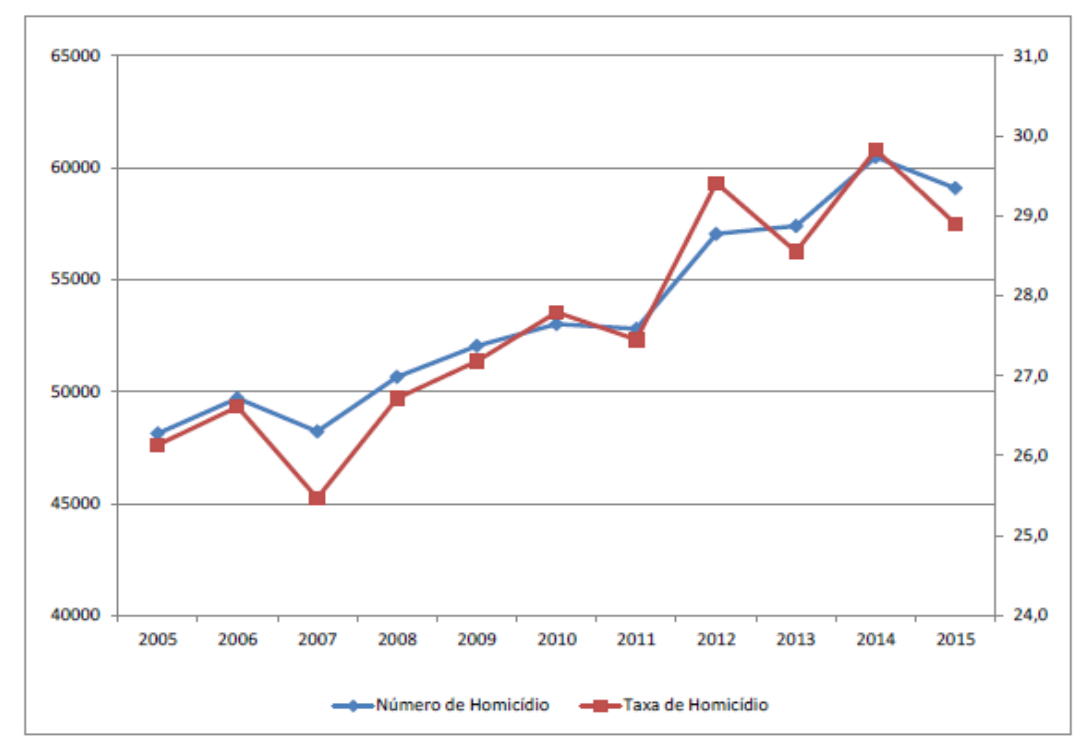

Fonte: IBGE/Diretoria de Pesquisas. Coordenação de População e Indicadores Sociais. Gerência de Estudos e Análises da Dinâmica Demográfica e Sim/Dasis/SVS/MS. O número de homicídios foi obtido pela soma das seguintes CIDs 10: X85-Y09 e Y35-Y36, ou seja: óbitos causados por agressão mais intervenção legal. Elaboração Diest/Ipea.

A sociedade brasileira, com seus elevados níveis de pobreza e desigualdade social, bem como características culturais e sociais permeadas pela prática de violência e afronta à dignidade da pessoa humana, torna-se um ambiente desafiador para a afirmação continuada de ações na defesa e a garantia dos Direitos Humanos. Waksnman e Harada (2010) realizaram pesquisa junto a famílias sobre modos de educar seus filhos e $40 \%$ afirmaram impor sua vontade sobre a prole; com relação às crianças, 57\% apanharam dos pais, em situações de imposição de limites. Quanto às atitudes adotadas pelos pais dos entrevistados para a resolução de problemas do cotidiano familiar, 57\% responderam que usavam a força física; 19\% conversavam; $15 \%$ castigavam e $7 \%$ utilizavam a repreensão verbal por meio de gritos e palavras inadequadas.

Alguns órgãos como a Organização Mundial de Saúde (2003), ressaltam a importância de se discutir a violência como um problema pluricausal, isto é, com muitas causas, sejam elas provenientes de: fatores biológicos e pessoais; fatores relacionais; fatores comunitários; fatores sociais mais amplos, acrescentando ainda a fragilidade das Políticas Públicas de educação, saúde, econômicas e sociais que contribuem para manter a desigualdade, ou seja, a violência estrutural (o não acesso aos serviços). Resumindo, podemos dizer que a violência está intimamente ligada aos fatores: biológico, subjetivo e social.

No Brasil, especificamente no ano 2000, os internamentos hospitalares decorrentes de violência chegaram a índices altíssimos, por lesões e traumas provenientes de acidentes e violências que alcançaram o sétimo lugar no conjunto de internações (MINAYO, 2004). Segundo o Datasus, em 2005 os acidentes e as violências foram responsáveis por mais de $20 \%$ das mortes em crianças de 1 a 5 anos, cerca de $40 \%$ nas de 5 a 9 , mais de $50 \%$ entre 10 e 15 e $75,6 \%$ de 15 a 19 anos, representando o primeiro lugar entre os óbitos nessas idades e a terceira causa entre todos os óbitos ocorridos no Brasil (WAKSNMAN; HARADA, 2010).

É preciso esclarecer que esses casos foram os notificados, fora os que ocorrem no silêncio, nas quatro paredes das casas, em instituições de longa permanência para idosos, de violência intrafamiliar contra a mulher, à criança, e das mais diversas formas de violência na área de saúde mental, dos usuários que 
não possuem um serviço especializado de atendimento as suas demandas.

A superação do problema da violência contra crianças e adolescentes requer o envolvimento de todos os segmentos da sociedade, que deve assumir o compromisso de empreender uma mudança de cultura a médio e longo prazo sobre os vários aspectos que a envolvem.

Nesse contexto, o relatório da Assembleia Geral das Nações Unidas, de 2006, sobre a violência, pontua a necessidade do fortalecimento de compromissos nacionais e internacionais sobre o combate a formas de violência, promoção de valores não violentos, criação de sistema de denúncias, responsabilização dos agressores, sendo que as ações de prevenção devem ser priorizadas.

O compromisso assumido pelo Estado brasileiro desencadeou no conjunto de respostas de políticas públicas na última década visando modificar o cenário de violência. Apenas para citar dois exemplos, vamos abordar o tema da violência na perspectiva da mulher e da criança e do adolescente.

No âmbito da violência contra mulher, a lei 11.340/2006, chamada lei Maria da Penha, em homenagem à mulher que após sobreviver a tentativas de homicídio na década de 1980 por parte do então marido, lutou durante décadas junto à sociedade e órgãos políticos para a criação de mecanismos para coibir a violência doméstica e familiar contra a mulher (FERNANDES, 2010). Essa lei criou Juizados de Violência Doméstica e Familiar, alterou código penal e de processo penal de modo a coibir com o máximo de agilidade a violência doméstica e familiar contra a mulher.

Em relação à criança, destaca-se a criação do sistema de garantia dos direitos da criança e do adolescente, através da resolução n¹13/2006 do Conselho Nacional dos Direitos da Criança e do Adolescente (CONANDA), que se constituiu como um sistema de serviços organizados para articular ações intersetoriais, especialmente nas áreas da saúde, educação, assistência social, trabalho, segurança pública e outras visando garantir promoção, defesa e controle para a efetivação dos direitos humanos da criança e do adolescente, nos níveis Federal, Estadual, Distrital e Municipal.

O cenário após dez anos dessas importantes iniciativas do poder público continua marcado por uma forte cultura de violência no país demonstrada pelo conjunto de indicadores sociais produzidos nas diversas instituições atuantes.

O Instituto Datafolha apresentou dados sobre violência contra mulher no ano de 2016. Segundo a pesquisa, uma em cada três mulheres sofreram algum tipo de violência no ano de 2016 e que entre elas, 52\% se calaram, $11 \%$ procuraram uma delegacia da mulher e 13\% preferiram o auxílio da família. Das situações de violência, o estudo indicou que os casos de agressão mais graves ocorrem dentro de casa da mulher, em $43 \%$ dos casos, ante 39\% nas ruas. Os dados são bastante expressivos e ainda são mais preocupantes quando se considera que esses dados ainda são subnotificados. Em 2016 tramitaram na Justiça Estadual do país 1.199.116 processos referentes à violência doméstica contra a mulher, o que corresponde, na média, a 11 processos a cada mil mulheres, ou 1 processo a cada 100 mulheres brasileiras (CNJ, 2017).

Em relação à violência contra crianças e adolescentes, os homicídios entre crianças e jovens de 0 a 19 anos aumentaram quase 20 vezes entre 1980 e 2013, passando de 0,7 para 13,9\%. Em 2010, o Sistema de Informação de Agravos de Notificação (SINAN) registrou 12.473 notificações de violência contra crianças menores de 10 anos. Apenas no primeiro trimestre de 2015, foram feitas 21.021 denúncias de violação de direitos pelo Disque Denúncia 100, do governo federal. No Paraná, em 2014, foram registradas 19.547 notificações de violência contra crianças e adolescentes; em 2016, essa taxa aumentou 26\%, somando 24.244 casos (WAISELFISZ, 2015).

A partir da concepção da violência enquanto fenômeno multicausal, e do reconhecimento do conjunto de compromissos e ações assumidas pelo poder público para seu enfrentamento, há de se reconhecer o padrão violento na própria cultura contemporânea. Diante desse cenário, busca-se discutir a importância da assimilação dessa concepção em projetos de atendimento às famílias, considerando o viés social da violência, ao lado de seu viés cultural. Nesse sentido, a ação envolvendo a disseminação da Cultura da Paz se torna relevante. 


\section{CULTURA DA PAZ - UMA EDUCAÇÃO PARA O RECONHECIMENTO DOS DIREITOS HUMANOS}

A afirmação de uma cultura de paz envolve a afirmação de um conjunto de valores, atitudes e comportamentos, em detrimento de outros tantos valores, atitudes e comportamentos presentes em uma dada sociedade. A expressão remete a afirmação de uma cultura que respeite a dignidade humana nos hábitos mais simples da vida cotidiana, a partir do reconhecimento universal aos direitos fundamentais. Nesse sentido, cultura da paz pode ser entendida como a maneira de agir e pensar, individual e coletiva, direcionada para a criação de hábitos, costumes e atitudes de respeito, bem como para a resistência a palavras, gestos e atos de agressão (BRASIL, 2000).

$\mathrm{O}$ século XX, conforme atestam historiadores e sociólogos, foi um período de mudanças extremas nas formas de viver e se relacionar em sociedade. Revoluções sociais, ditaduras, duas grandes guerras sem precedentes históricos (HOBSBAWM, 1998). De facto o século passado possuiu contornos sociais onde a vida humana assumiu um valor inigualável. A $2^{\circ}$ Guerra Mundial devastou dezenas de países e tomou a vida de milhares de seres humanos, e ao final dela, despertou na comunidade internacional a necessidade de se encontrar uma forma de manter a paz entre os países $^{2}$.

Em 1945 foi instituída a Organização das Nações Unidas (ONU). Criada para atuar na promoção da paz e assistência humanitária, a ONU passou a ser uma central de esforços internacionais para unir nações e harmonizar ações, na busca de soluções pacíficas para os problemas humanos. Nesse contexto, a construção de uma sociedade pacífica é assimilada pela agenda política internacional (ONU, 2013).

$\mathrm{O}$ ano 2000 foi definido como o ano internacional da cultura de paz, no qual ganhadores do prêmio Nobel da paz, junto a representantes da UNESCO e da ONU, uniram esforços para escrever um importante documento em que se definiram os princípios para a

\footnotetext{
${ }^{2}$ No desenrolar histórico desse período conturbado e de extrema violência se desenvolveram discussões e reflexões que possibilitaram reconhecer a relação contemporânea entre poder e o colonialismo e de se reconhecer relações de dominação e violência em escala mundial. Nessa vertente, problematiza-se a concepção de conhecimento e compreensão do mundo sem tomá-lo como natural a partir da explicação monocultural eurocêntrica. A partir disso torna-se possível reconhecer diferentes lógicas de organização social em diferentes sociedades. (MENESES, 2010).
}

criação de uma cultura de paz, o chamado Manifesto 2000 por uma cultura de paz e não-violência.

Nos dias de hoje, a educação em direitos humanos e para a paz - concebida em sua tripla finalidade de informar, formar e transformar - constitui um importante instrumento de construção de uma nova cultura, aspiração antiga na sociedade e na história da educação, assimilada e integrada transversalmente, por algumas reformas educacionais em todo o mundo (GORCZEVSKI; TAUCHEN, 2008).

$\mathrm{Na}$ medida em que o tema da cultura de paz se insere como eixo no Plano Nacional de Educação em Direitos Humanos, aprovado em 2006, novas ações são esperadas nas redes de ensino e nas Universidades, mas também nas creches, nas fábricas, nos centros comunitários, ou seja, em todo e qualquer lugar onde a convivência é posta em questão, para a aprendizagem de valores interpessoais pautados no respeito e na diversidade.

Baseados nos escritos de Paulo Freire:

A cultura da paz se constitui dos valores, atitudes e comportamentos que refletem o respeito à vida, a pessoa humana e a sua dignidade, aos direitos humanos, entendidos em seu conjunto, interdependentes e indissociáveis. Viver em uma cultura de paz significa repudiar todas as formas de violência, especialmente a cotidiana, e promover os princípios da liberdade, justiça, solidariedade e tolerância, bem como estimular a compreensão entre os povos e as pessoas (apud MILAN, 2003, p.36).

Diante disso, pensar em cultura da paz é pensar na consciência permanente dos valores da não violência social. Cultura da paz vai para além de construir paz, pressupõe a resolução pacífica de conflitos, numa mudança de paradigma.

Para o entendimento da relação entre cultura da paz e política de assistência social, destacamos abaixo uma breve contextualização da assistência social, a qual permitirá aproximar o tema da educação para a paz como ferramenta para o atendimento ao público-alvo desta Política Pública.

\section{CONTEXTUALIZAÇÃO DA POLÍTICA DE ASSISTÊNCIA SOCIAL}

Com a promulgação da Constituição de 1988, muitos autores destacaram os avanços com relação aos direitos sociais. A assistência social que anteriormente 
era direcionada pela benesse, filantropia e/ou assistencialismo passou a ter o patamar de Política Pública, isto é, dever do Estado e direito do cidadão. A carta magna formaliza a assistência social na seguridade social.

Conforme o artigo 194 " [...] a seguridade social compreende um conjunto integrado de ações de iniciativa dos Poderes Públicos e da sociedade, destinado a assegurar os direitos relativos à saúde, à previdência $\mathrm{e}$ à assistência social". No artigo 203, se prevê o direito à assistência social aos que dela necessitarem, tendo como objetivos desta Política Pública:

I - a proteção à família, à maternidade, à infância, à adolescência e à velhice; II - o amparo às crianças e adolescentes carentes; III - a promoção da integração ao mercado de trabalho; IV - a habilitação e reabilitação das pessoas portadoras de deficiência e a promoção de sua integração à vida comunitária; $\mathrm{V}$ - a garantia de um salário-mínimo de benefício mensal à pessoa portadora de deficiência e ao idoso que comprovem não possuir meios de prover à própria manutenção ou de tê-la provida por sua família, conforme dispuser a lei (CONSTITUIÇÃO FEDERAL, 1988).

A fim de regulamentar tais objetivos foi sancionada a Lei Orgânica da Assistencial (LOAS), Lei 8.742, em 07 de dezembro de 1993. Esta lei ratificou a assistência social como "direito do cidadão e dever do Estado". Esta lei iniciou o processo de construção da Política Pública de assistência social no Brasil, no campo dos direitos da universalização dos acessos, e da responsabilidade estatal.

No ano de 2004 o Conselho Nacional de Assistência Social aprovou a Política Nacional de Assistência Social (PNAS), através da Resolução n ${ }^{\circ}$ 145, de 15 de outubro de 2004. A PNAS, “[...] busca incorporar as demandas presentes na sociedade brasileira no que tange à responsabilidade política, objetivando tornar claras suas diretrizes na efetivação da assistência social como direito de cidadania e responsabilidade do Estado" (BRASIL, 2005 p.13).

A PNAS introduziu a lógica da Proteção Social em níveis de proteção, sendo organizada em proteção social básica e especial. Definiu quais as seguranças que devem ser afiançadas, ou seja, segurança de sobrevivência, que contempla algumas garantias ao cidadão; segurança de rendimento e autonomia; de acolhida; de convivência familiar e comunitária.
Apresentou os equipamentos públicos estatais onde devem ser incluídos os usuários de seus serviços (BRASIL, 2005).

A proteção social deve ser entendida como um conjunto de políticas ou programas que visam amparar indivíduos e famílias que se encontrem em alguma situação de vulnerabilidade. Ela deve ser vista ainda como um dos principais elementos estratégicos para a superação das mais diversas formas de vulnerabilidades sociais (SOUSA, 2016).

Segundo Sposati (2009), o campo da proteção social é o campo em que se efetivam as seguranças sociais. Para a autora, há um campo de forças entre as concepções e interesses na construção e implementação de uma política social. Nesta relação de forças, uma concepção busca configurar a assistência como política de Estado (dever); a outra busca configurá-la como princípios da subsidiaridade (o direito), ou seja, o Estado deve ser o último e não o primeiro a agir. Nesta segunda perspectiva prevalece o princípio da solidariedade, como ação de entidades subvencionadas pelo Estado; perspectiva esta de redução do estado na área social.

No intuito da organização da política de assistência social, o Ministério de Desenvolvimento Social e Combate à Fome, junto com o Conselho Nacional de Assistência Social, desenham o Sistema Único de Assistência Social - SUAS, “[...] cujo modelo de gestão é descentralizado e participativo, constitui-se na regulação e organização em todo o território nacional das ações socioassistenciais. Os serviços, programas, projetos e benefícios têm como foco prioritário a atenção às famílias, seus membros e indivíduos e o território como base de organização" (BRASIL, 2005, p.39).

Segundo a Política Nacional de Assistência Social de 2004, o público usuário da Política de assistência social, constitui-se de cidadãos e grupos que se encontram em situação de vulnerabilidade social e riscos. O SUAS preconiza um novo olhar em relação às famílias e seus indivíduos, possibilitando o conhecimento das vulnerabilidades/riscos sociais que vivenciam em seu território, além de buscar o fortalecimento de vínculos familiares e comunitários, potencializando a capacidade protetiva da família no cuidado de seus membros, bem como, promovendo sua autonomia e protagonismo dos sujeitos.

O Sistema Único de Assistência Social se estrutura através de eixos constituídos: matricialidade 
sociofamiliar; descentralização político-administrativo e territorialização; Novas bases para a relação entre Estado e sociedade civil; financiamento; controle social; desafio da participação popular/cidadão usuário. (BRASIL, 2005)

A política de assistência social, numa perspectiva de superação da assistência social fragmentada, com ações isoladas, imediatistas, tem sua centralidade na família, considerando-a como espaço privilegiado de proteção e socialização.

Esta ênfase está ancorada na premissa de que a centralidade na família e a superação da focalização, no âmbito da política de Assistência Social, repousam no pressuposto de que para a família prevenir, proteger, promover e incluir seus membros é necessário, em primeiro lugar, garantir condições de sustentabilidade para tal. Nesse sentido, a formulação da política de Assistência Social é pautada nas necessidades das famílias, seus membros e dos indivíduos (BRASIL, 2005, p.41).

Este eixo, matricialidade sócio familiar, estabelece as ações da política de assistência social na intervenção sobre a família, contrapondo-se a lógica individual. Neste contexto, a centralidade da família "[...] reforça a importância da política de Assistência Social no conjunto protetivo da seguridade social, como direito de cidadania, articulada a lógica da universalidade" (BRASIL, 2005, p.42).

"A família, independente dos formatos ou modelos que assume, é a mediadora das relações entre os sujeitos e a coletividade, [...] bem como geradora de modalidades comunitárias de vida" (BRASIL, 2005 , p.41). No entanto, não se pode desconsiderar que ela se caracteriza como um espaço contraditório, cuja dinâmica cotidiana de convivência é marcada por conflitos e geralmente, também, por desigualdades (BRASIL, 2005, p.41).

Em 2011 é promulgada a Lei 12.435, a qual traz alterações e definições importantes, dispõe sobre questões de organização da Assistência Social, alterando a LOAS (1993) e principalmente institui o SUAS como Lei.

Como já mencionado, a política de assistência social está organizada por tipos de proteção, denominadas de proteção social básica e proteção social especial. A proteção social especial objetiva desencadear estratégias de atenção sociofamiliar em determinadas situações de vida que proporcionem condições para a elaboração de novas referências no sentido de fortalecer o exercício de proteção básica, auto-organização e autonomia:

\begin{abstract}
A proteção social especial é a modalidade de atendimento assistencial destinada a famílias e indivíduos que se encontram em situação de risco pessoal e social, por ocorrência de abandono, maus tratos físicos e, ou, psíquicos, abuso sexual, uso de substâncias psicoativas, cumprimento de medidas sócio-educativas, situação de rua, situação de trabalho infantil, entre outras (BRASIL, 2005, p.37).
\end{abstract}

Nesta perspectiva, a proteção social especial, como parte da assistência social, promove atenções e orientações direcionadas para a promoção de direitos, a preservação e o fortalecimento de vínculos familiares, comunitários e sociais e para o fortalecimento da função protetiva das famílias diante do conjunto de condições que as vulnerabilizam e/ou as submetem a situações de risco pessoal e social.

A partir de uma reflexão ampliada sobre o fenômeno da violência, cultura de paz e assistência social, discute-se a seguir metodologias de trabalho que podem balizar e oferecer parâmetros para o enfrentamento das violências presentes no âmbito familiar e comunitário. Para tanto, pensou-se em princípios da educação para a paz direcionando o trabalho com famílias na proteção social especial.

\section{EDUCAÇÃO PARA A PAZ: ALTERNATIVA DE TRABALHO COM FAMÍLIAS}

"A Educação para os Direitos Humanos é um processo de longo prazo, trata-se de uma educação permanente, global, complexa e difícil, mas não impossível. É, certamente, uma utopia, mas que se realiza na própria tentativa de realizá-la" (BRASIL, 2012)

No ano de 2012, em um município de pequeno porte I, localizado na região dos Campos Gerais-PR, o Departamento de Proteção Social Especial estava subordinado à Secretaria Municipal de Assistência Social (SMAS) é era responsável pelo desenvolvimento das ações de proteção social especial no Município nas modalidades de média e de alta complexidade. A SMAS estava organizada da seguinte forma: 


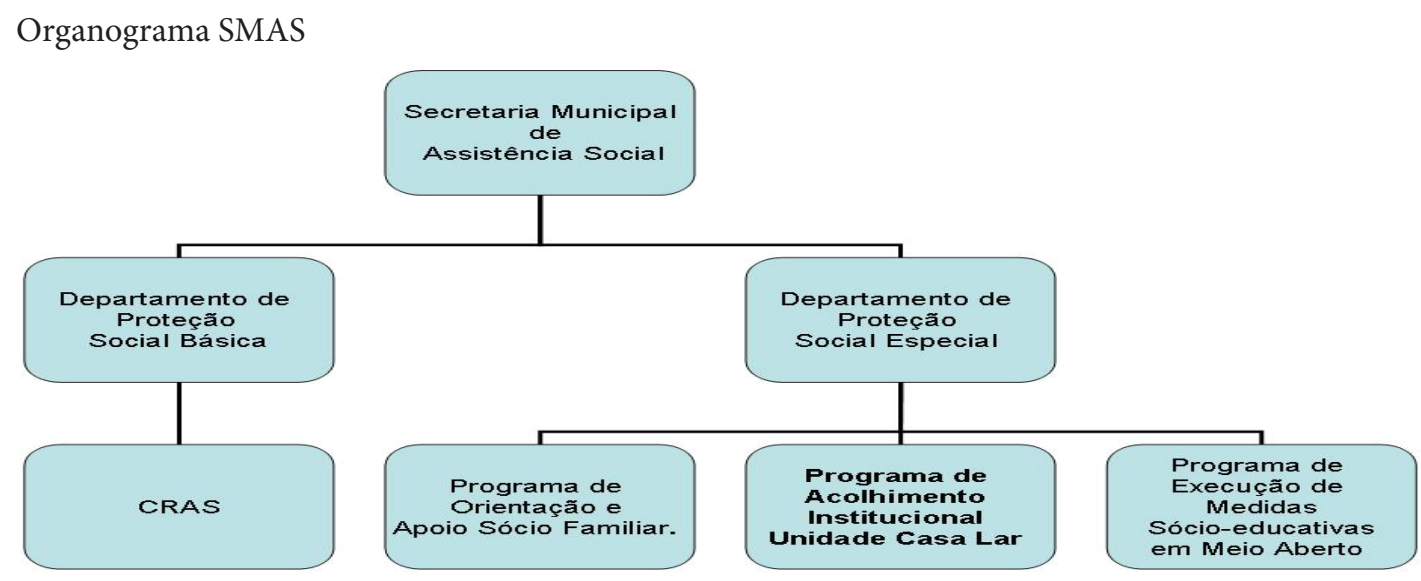

Fonte: Organograma da Secretaria Municipal de Assistência Social organizado pelo autor

Após encontros coletivos entre as equipes multiprofissionais dos serviços de proteção social especial, gestão municipal e da rede socioassistencial foram apresentas as novas diretrizes para o trabalho social com famílias nos serviços de proteção social especial. Naquele contexto, identificava-se grande dificuldade para a prestação dos serviços de acompanhamento sociofamiliar se desse em conjunto com ações de defesa e garantia de direitos. Trabalhando com uma linguagem clara e objetiva foram apresentados os complexos princípios e conceitos envolvidos na proposta de uma cultura da paz, contidos nos tratados e acordos internacionais de direitos humanos. A justificativa se deu pelo aumento e diversificação do fluxo de encaminhamentos nos últimos anos para atendimento de famílias em situação de violações de direitos dirigidos a criança e adolescentes, bem como outros sujeitos como mulheres vítimas de violência, idosos em situação de violação, itinerantes e população de rua.

O trabalho foi planejado após análise da realidade local e das demandas por trabalho social junto das famílias atendidas pelo serviço. Identificou-se a presença de um conjunto de valores e atitudes que favoreciam a fragilização e/ou rompimento de vínculos familiares. Da mesma forma, observou-se que tal situação perdurava apesar da utilização de metodologias convencionais de acompanhamento familiar às quais não tinham sido exitosas, até aquele momento. Em relação às metodologias convencionais, destacamos os atendimentos individualizados, as visitas domiciliares, orientação aos membros da família e articulação com a rede socioassistencial.
A equipe de proteção social especial de média complexidade era formada à época por profissionais das áreas de pedagogia, psicologia e serviço social e a partir de planejamento conjunto, desenvolveu uma metodologia de trabalho baseada nos dez passos para uma cultura da paz. Deu-se início a uma nova proposta de trabalho, rompendo o paradigma do atendimento focalizado na aquisição de indivíduos e famílias, passando a se assimilar a dimensão da mudança cultural.

A partir da definição de utilização da cultura de paz como tema organizador, o trabalho social passou a dividir os participantes em grupos e as atividades foram sendo organizadas a partir dos dez passos para uma cultura da paz: I. Reunir; II. Dialogar; III. Tomar consciência; IV. Aceitar o diferente; V. Escolher; VI. Aprender; VII. Ser justo; VIII. Responsabilizar-se; IX. Cuidar; X. Modo de ser.

Foram organizados três grupos: o primeiro grupo foi formado por adultos, chefes de família, pais ou responsáveis legais de crianças e/ou adolescentes (maior grupo). Foram realizados oito encontros abordando os 10 passos; o segundo e terceiro grupos foram formados por adolescentes, divididos em dois grupos, com eles foram realizados quatro encontros cada, a partir de quatro eixos centrais: 'modo de ser', 'aprender', 'conscientizar-se' e 'fazer escolhas'.

O desenvolvimento das atividades se deu através de pequenas oficinas planejadas em torno de um tema ou dois temas principais, seguida de rodas de conversa, onde se permitiria a fala sobre as situações vivenciadas no cotidiano familiar, a critério de cada participante. As atividades foram desenvolvidas pelos profissionais responsáveis pela proposta, pelas 
estagiárias do serviço e contou com a participação de outros profissionais convidados.

O primeiro encontro foi para apresentar a proposta, ouvir os participantes e expor os dez passos para uma cultura da paz. Posteriormente, seguiu-se o cronograma de atividades propostas adentrando nos temas ordenados pelos materiais de apoio.

Especificamente com as famílias, discutiu-se o tema: "Reunir e Dialogar", o que permitiu observar que muitas delas já não conseguiam se reunir em família, e pouco dialogavam com seus filhos. Estabeleceuse um contrato com os participantes em que os mesmos se propuseram a exercitar os momentos de se reunirem com maior frequência em suas casas, seja num momento de refeição, seja num momento de lazer. A proposta deste encontro foi: Criar espaços para dialogar.

Outro encontro também relevante foi marcado pela presença de uma convidada da área da Pedagogia e trabalhou com os temas: "Cuidar e Responsabilizarse", a partir de uma perspectiva de ações coletivas. Utilizou-se de desenho livre, em que cada participante deveria complementar o desenho dos demais, os participantes inicialmente demonstraram certa apreensão com a atividade, mas ao final o resultado foi positivo e os participantes consideraram que conseguiram se reconhecer como parte de um grupo maior. Esta atividade propiciou a visão que o cuidar envolve a responsabilização coletiva do grupo, se houver competição entre os membros, o grupo perderá como um todo.

Em outra atividade com o tema "Aprender" utilizou-se da metodologia de se fazer o "fuxico" (artesanato), para posteriormente ir juntando peça por peça, até formar um só material, a fim de possibilitar aos participantes um momento de construção de objeto e reflexão sobre o dialogar, reunir e partilhar. Esse momento foi de extrema importância na discussão do aprender a fazer, aprender a se relacionar, aprender a construir algo diferente do que estavam acostumados.

Quando abordamos o tema "Conscientizar-se e Fazer Escolhas", toda equipe deu sua contribuição, realizando uma dramatização sobre um fato narrado o qual envolvia situações de confrontos familiares e mediação de conflitos. Houve uma sensibilização dos participantes que se identificaram com a temática abordada. De olhos fechados foram sentindo a dramatização, as falas, os momentos de conflito; situação que proporcionou aos participantes interagir e se sentir parte do contexto.

Outros encontros realizados tiveram como temas o "Respeito às Diferenças", o "Senso de Justiça", bem como, um encontro especificamente dirigido ao tema da adolescência, o qual foi relacionado ao assunto "Aprender".

Utilizando-se de dinâmicas de grupo, textos e exposição oral, confecção de cartazes os participantes puderam manifestar suas dificuldades e enfrentamentos das questões do cotidiano. Em alguns momentos utilizou-se da mediação das falas dos participantes pelo profissional designado para a oficina, visando dimensionar as histórias de vida, o conjunto de dificuldades vivenciadas, como algo não somente de caráter individual, mas também como parte de algo também coletivo. Diante dos temas os participantes puderam repensar suas atitudes com seus pares, comunidade, seus filhos, e como poderiam resgatar algumas atitudes que ficaram no esquecimento, como a qualidade do tempo reservado à família.

Simultaneamente ao trabalho com as famílias foram realizados os encontros com os adolescentes, os quais num primeiro momento tiveram resistência em participar do grupo, sendo necessário realizar ações de sensibilização e motivação dos adolescentes em domicílio, para sua participação. A iniciativa foi eficaz e permitiu o desenvolvimento do trabalho social com os dois grupos de adolescentes.

As duas oficinas fizeram parte do projeto de intervenção de duas estagiárias, uma de psicologia e outra de serviço social, sendo realizado sob a supervisão dos técnicos de referência do serviço. Após a primeira oficina para o acolhimento dos adolescentes, apresentação da proposta e escuta de sugestões pelo grupo, seguiu-se a exibição do filme "Aos Treze", que aborda o tema do mundo das drogas, sexo e roubos na pré-adolescência. Esse momento foi muito importante para constituir o vínculo de confiança do grupo e aproximação dos adolescentes com a equipe de estagiárias. Uma das oficinas seguintes construir um trabalho de criação e discussão sobre o "Conscientizar-se", entendendo que ninguém conscientiza ninguém, sendo um processo subjetivo de indagação do próprio "Eu" e das situações vivenciadas coletivamente. Utilizou-se da argila, como recurso para moldar e refletir o mundo.

As estagiárias tiveram papel relevante no desenvolvimento desta proposta de trabalho, desenvolvendo 
oficinas com os adolescentes numa linguagem acessível, comprometida com as escolhas desta faixa-etária.

Em meio ao desenvolvimento das oficinas junto das famílias, a equipe multidisciplinar manteve-se em constante diálogo, reunindo-se para discutir e analisar cada encontro. Da mesma forma, buscou-se objetivar e identificar os impactos decorrentes do trabalho social realizado, no cotidiano familiar e comunitário das famílias, bem como no cotidiano do próprio serviço. O primeiro resultado identificado foi a participação continuada das famílias nos encontros, uma maior abertura para expressar suas percepções e relatar experiências cotidianas relacionadas aos temas abordados, ou não. Em relação à equipe, notou-se maior presença do trabalho criativo, aproximação e fortalecimento de vínculos entre a equipe, bem como percepção de aumento no nível de satisfação em relação ao trabalho.

Ao final do processo de trabalho, foi realizada uma autoavaliação entre os participantes e equipe, na qual foi possível identificar que um conjunto de valores e práticas envolvidas nos 10 passos para a cultura da paz esteve entre os conteúdos mencionados pelos participantes das oficinas. De forma objetiva, observou-se que aspectos e situações das relações familiares não vulnerabilizam ou colocaram os indivíduos e as famílias em risco, as situações acompanhadas não se agravaram ao longo do período em que o trabalho social foi realizado junto a essas famílias.

\section{CONSIDERAÇÕES FINAIS}

Bem sabemos que a "cultura da paz" tem seu enfoque ideológico de fomentar a harmonia coletiva e principalmente a disseminação de práticas coletivas e o reconhecimento do princípio da dignidade humana como fundamental para uma sociedade mais solidária e menos violenta.

O desenvolvimento do trabalho social abordando a "cultura da paz" permitiu o desenvolvimento de encontros diferenciados com as famílias e os jovens envolvidos em situação de conflito e violência familiar e comunitária. A proposta inicial da equipe multidisciplinar foi de trazer momentos de reflexão aos participantes sobre a não violência, e outras formas de se relacionarem sem instigar o desrespeito, a afronta, o conflito agressivo. Ao longo do trabalho observamos que através desse recurso foi possível um diálogo maior entre grupos e a verbalização dos participantes de forma mais simples e espontânea. Simultaneamente, o trabalho sendo desenvolvido com os responsáveis pelas famílias e os adolescentes trouxe um ganho maior no sentido de aproximar as partes envolvidas através de conteúdo comum, não por meio de uma metodologia rígida, com um discurso pronto, mas por meio da organização de espaços de convivência e da seleção de temas e conteúdos que favoreceram a reflexão e construção coletiva diante das situações vivenciadas.

A experiência apresentada acima nos deu ainda mais propriedade para afirmar a potencial relação que existe entre o SUAS e cultura de paz. A política de assistência social pode ser considerada ainda muito recente, sua identidade, enquanto alinhamento teórico e metodológico, vem se constituindo em meio ao conjunto de estratégias, visando o enfrentamento às desigualdades na sociedade brasileira. Nesse sentido, a afirmação que há grande potencial de transformação da dinâmica sociofamiliar e comunitária através da utilização dos princípios norteadores da cultura da paz nos serviços de proteção social especial pode contribuir para avanços nessa política pública e no fortalecimento da cultura de não violência na sociedade brasileira.

\section{REFERÊNCIAS}

BOCK, A. M. Formação do Psicólogo: Um Debate a Partir do Significado do Fenômeno Psicológico. Psicologia Ciência e Profissão, 1997, 17, (2), 37-42.

BRASIL. Dez Passos para a Construção de um Caminho para a Cultura da Paz. Disponível em: <http://www. sociedadesemear.org.br/arquivos/20110615171832_17-ca rtilhaconstru $\% \mathrm{C} 3 \% \mathrm{~A} 7 \% \mathrm{C} 3 \% \mathrm{~A} 3$ odepazneca.pdf $>$. Acesso em: jun. 2018.

- Ministério do Desenvolvimento Social e Combate a Fome. Lei Orgânica da Assistência Social-LOAS, Brasília - DF, 1993.

Constituição da República Federativa do Brasil: promulgada em 5 de outubro de 1988. 2015.

Lei $n^{\circ} 8.742$ de 1993. Lei Orgânica da Assistência Social: dispõe sobre a organização da Assistência Social e dá outras providências. SUAS/PR - Instrumentos Legais. Brasília: [s. n.], 2008.

Lei $n^{\circ}$. 12.435 de 2011. Sistema Único de Assistência Social: altera a lei 8.742 que dispõe sobre a organização da Assistência Social. 2011. 
CERQUEIRA, D.; LIMA, R. S.; BUENOS, S.; VALENCIA, L.I.; HANASHIRO, O.; MACHADO; P.H.G.; LIMA, A.S. Atlas da Violência 2017. $2^{\circ}$ Ed. Rio de Janeiro: IPEA, 2017. Disponível em: <http://www.ipea.gov.br/atlasviolencia/ download/2/2017. Acesso em: jun. 018.

CONSELHO NACIONAL DE JUSTIÇA. O Poder Judiciário na Aplicação da Lei Maria da Penha. Brasília, 2017. Disponível em: <http://www.cnj.jus.br/files/conteudo/ arquivo/2017/10/ba9a59b474f22bbdbf7cd4f7e3829aa6. pdf $>$. Acesso em: jun. 2018.

FERNANDES, M da P. M. Sobrevivi...posso contar. Fortaleza: Armazém da Cultura: 2010.

FREIRE, Ana Maria Araújo. Educação para a paz segundo Paulo Freire. Disponível em: http://revistaseletronicas. pucrs.br/ojs/index.php/faced/article/viewFile/449/345>. Acesso em: jun, 2018.

GORCZEVSKI, Clovis.; TAUCHEN, Gionara. Educação em Direitos Humanos: para uma cultura da paz. Educação, Porto Alegre, v. 31, n. 1, p. 66-74, jan./abr. 2008.

HOBSBAWM, Eric. A Era dos Extremos: o breve século XX. São Paulo: Companhia da Letras, 1998.

MENESES, Maria Paula G. Corpos de violência, linguagens de resistência: as complexas teias de conhecimento no Moçambique contemporâneo. In SANTOS, Boaventura de Sousa. Epistemologias do Sul, Ed. Cortez, 2010.

MINAYO. Maria Cecília de Souza. Violência: um tema que a realidade social impõe a atenção médica. Ciência e Saúde Coletiva. Revista Digital de Educação Permanente em Saúde. (periódico na internet), pág. 1-3, 2004.

- A inclusão da violência na agenda da saúde: trajetória histórica. Ciência e Saúde Coletiva. Base de dados LILACS, p.1259-1267, 2006. Disponível em: http://bases. bireme.br/cgi-bin/wxislind.exe/iah/online/?IsisScript=iah/ iah. $x i s \&$ nextAction $=$ lnk\&base $=$ LILACS\&exprSearch $=471$ 490\&indexSearch=ID\&lang=p. Acesso em 09/05/2018.

. O significado social e para a saúde da violência contra crianças e adolescentes. In: Westphal MF, org. Violência e criança. São Paulo: Editora da Universidade de São Paulo (USP); 2002.

MINISTÉRIO DO DESENVOLVIMENTO SOCIAL E COMBATE A FOME. Política Nacional de Assistência Social: norma operacional básica (NOB/SUAS). Brasília, nov, 2005.

SOUSA, R. P. Proteção social. In: ROSA, M. C.; FERNANDES, A. H. (org.) Dicionário crítico: política de assistência social no Brasil. Porto Alegre: Ed. UFRGS, 2016, p. 226.

SPOSATI. Aldaíza. Especificidade e intersetorialidade da politica de assistência social. In: Serviço Social e Sociedade no. 77. São Paulo: Cortez, 2004.
SPOSATI. A. Modelo brasileiro de proteção social não contributiva: concepções fundantes. In: Concepção e Gestão da Proteção Social Não Contributiva no Brasil. Brasília, Ministério do Desenvolvimento Social e Combate à Fome. UNESCO, 2009.

WAISELFISZ, J.J. Mapa da violência 2015: mortes matadas por arma de fogo. Brasília: UNESCO/, 2015. Disponível em: $\quad<$ http://www.mapadaviolencia.org.br/pdf2015/ mapaViolencia2015.pdf $>$. Acesso em: 17 jun. 2018:

WAKSNMAN, Renata Dejtiar; HARADA, Maria de Jesus Castro. Violência contra a criança e o adolescente. Manual de Atendimento às Crianças e Adolescentes Vítimas de Violência. Núcleo de estudos da violência doméstica contra crianças e adolescentes da Sociedade de Pediatria de São Paulo, 2010. 